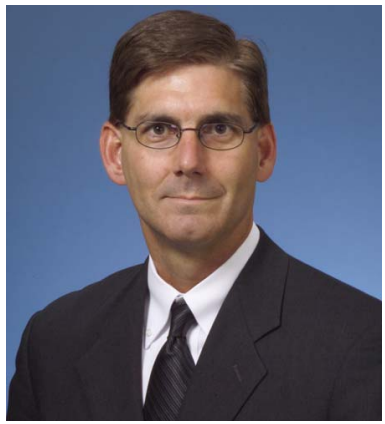

\section{Nearing Retirement? A Call for Tutorial and Review Papers}

In college, I remember being surprised when I was approached by a professor, Dr. Carl Halford (who eventually became my major professor), about my attending graduate school. I came from a relatively poor family and had never considered any other path than to secure a well-paying optical engineering position. Dr. Halford not only convinced me to attend graduate school, but arranged internship support for me through teaching undergraduate classes. His primary advice to me at the time pertained to my perspective toward school. He had felt that I spent too much time worrying about grades and going through the systematic motions of obtaining a successful education. His demand of me prior to doctoral studies was "to quit worrying about grades, open your mind and try to learn something, and have fun." It is a demand that every graduate student in science and engineering should hear and one that I cherish to this day. By the way, if you are trying to learn something and are having fun, the grades actually follow.

Dr. Halford retired this past June among a swelling wave of highly successful senior electro-optical and photonic engineers and scientists. In the next 3 to 4 years, there is a large population of brilliant optical engineers and scientists that will join the retired community. Many government charts over the past five years have shown this retirement wave as a swell with very few science and engineering hires in the 15 years following this swell. That is, there is a 15-year gap where very few engineers and scientists were educated and obtained jobs in the area of electro-optics and photonics. There are a number of suggested reasons for the gap, but I have seen enough data to be convinced that this bimodal distribution is real (and it extends beyond electro-optics and photonics).

In this editorial, I am making a plea for senior scientists and engineers nearing retirement to provide a tutorial paper or a review paper in an interesting and relevant subject in the area of optical engineering. I have personally asked and recruited a few people in this situation and I have received the typical "I don't have time" or "leave me alone" responses. However, I will remind you that the field of optical engineering has been good or even great to the majority of people who have had the pleasure of working in the area. It is the obligation of all of us to mentor those behind us, because we were mentored by those in front of us ("we stand on the shoulders of those who came before us"). I am sure it is not necessary for me to carry on about the importance of providing this service to our junior community. If you are not in the category that I describe, but you know someone who is perfect for this plea, then I would appreciate your help in determining the interest and (if appropriate) assisting in the convincing and recruiting of your senior colleague.

Tutorial papers have not been considered in Optical Engineering for years. I remember carrying one around on "How to Measure Modulation Transfer Function" for weeks many years ago when I was setting up a laboratory for testing the performance of the LANTIRN target acquisition imager on the F-16 aircraft. It was extremely useful and I lived and breathed it until my lab was functioning correctly. These tutorials are not to conflict with the SPIE Press Tutorial Texts Series in that the length of such a manuscript is a typical paper length of 12 pages or so. This is short enough to minimize the burden on a senior engineer or scientist nearing retirement; alternatively, the paper could be written shortly after retirement when more time allows.

In some cases, a review paper might be a better choice than a tutorial paper. In a review paper, the current research situation is explained and summarized over some recent period of time. For our senior colleagues who prefer to contribute a review paper, we are still very interested in those subjects that belong in Optical Engineering, and we would work with Bill Rhodes, the editor of SPIE Reviews, to arrange a joint publication between Optical Engineering and SPIE Reviews. In both cases, tutorial and review papers, the papers must go through the peer-review process to ensure quality and originality requirements.

I am urging those of you well-known senior scientists and engineers nearing retirement to provide mentorship here. Many of you will be sorely missed, and contributing in the above way would be appreciated more than you know. Please contact me if you would like to discuss a highly interesting and relevant tutorial or review paper that you could contribute.

Dr. Halford leaves a small army of optical engineers that continues to influence military, medical, and industrial electro-optics. He is not sure about what role he will play in any technical work, but lucky for me, he continues to be a great life mentor and leader. In fact, just a few years ago I was in a job that was very prestigious and a great opportunity, but I did not enjoy it. His advice, at odds with all my other friends and colleagues, was "if you are not happy, go do something else." It was the right advice.

Ronald G. Driggers Editor 